\title{
OS FÓRUNS PARTICIPATIVOS COMO ESPAÇOS PARA A PRÁTICA DA ECOCIDADANIA
}

\author{
Anna Carolina Victorino Vicente ${ }^{1}$ \\ Juliano Borghi de Mendonça² \\ Suzana Machado Padua ${ }^{3}$ \\ Maria das Graças de Souza ${ }^{4}$
}

Resumo: Esse artigo tem como objetivo compreender quais caminhos uma Educação Ambiental crítica pode oferecer para a promoção da ecocidadania no município de Uruçuca-BA. Partimos do pressuposto de que para transformar uma realidade para melhor é fundamental compreendê-la e debatê-la entre os diversos atores que podem influenciá-la. Por isso investigamos a contribuição de indicadores de sustentabilidade municipais e de fóruns participativos para o engajamento, a mobilização e a transformação socioambiental local, e constatamos a importância da existência de instituições locais que tenham como objetivo promover a cidadania em prol de uma melhor qualidade de vida para o alcance desses objetivos.

Palavras-chave: Educação Ambiental; Indicadores Municipais; Transformação Local; Fóruns Participativos; Ecocidadania.

\footnotetext{
1 Mestranda pela ESCAS - IPÊ (Escola Superior de Conservação Ambiental e Sustentabilidade ESCAS, do Instituto de Pesquisas Ecológicas - IPÊ). E-mail: annavcvicente@gmail.com

2 Mestrando pela ESCAS - IPÊ. E-mail: julianoborghi@yahoo.com.br

3 Professora da ESCAS e Presidente do IPÊ. E-mail: suzana@ipe.org.br

4 Coordenadora de Educação Ambiental do IPÊ. E-mail: gracinha@ipe.org.br
}

Revbea, São Paulo, V.11, № 2: 43-53, 2016.

revista brasileira educação ambiental 


\section{Introdução}

O momento histórico atual nos incita a refletir sobre o padrão de desenvolvimento que temos adotado ao longo dos últimos dois séculos - o qual nos trouxe muitos avanços em diversas áreas, como a medicina, a tecnologia, a agricultura, entre outros, mas que também está na raiz dos problemas enfrentados por diversas nações, como a pobreza, a fome, a deterioração do meio ambiente, e outros impactos evidenciados atualmente - e a decidir se queremos mantê-lo ou se adotaremos outro, que traga dentro de si a sustentabilidade e a ética como valores, a fim de garantir nosso futuro no planeta.

Desde o lançamento da Agenda $21 \mathrm{Global}$, documento que há um pouco mais de vinte anos alertou o mundo sobre os sinais de deterioração dos sistemas sociais, ambientais e econômicos decorrentes do caminho que estávamos trilhando, conseguimos avançar na mensuração dos nossos impactos e nas suas análises. Temos mais consciência das consequências positivas e negativas de nossa atuação na natureza e sociedade, mas ainda precisamos de muitos esforços na implementação de soluções que realmente nos ajudem a frear as mudanças globais e, consequentemente as locais, que enfrentamos e ameaçam a vida no planeta.

Porém, apenas podemos atuar em uma realidade a fim de transformá-la para melhorá-la se a conhecermos. Somente a conheceremos se a vivenciarmos e começarmos a entendê-la subjetivamente (suas percepções, histórias e necessidades) e objetivamente (levantando seus dados, organizando-os por meio de indicadores que façam sentido para seus habitantes e monitorando-os). Mas a melhoria de uma realidade só será possível a partir das pessoas que a compõe, se elas entenderem que é possível, se elas quiserem e se tiverem condições para isso.

Neste artigo temos o objetivo de entender como podemos promover ações cidadãs em prol da sustentabilidade no município de Uruçuca, alinhadas com os desafios globais, utilizando para isso indicadores de sustentabilidade reconhecidos e aceitos internacional e nacionalmente e a Educação Ambiental baseada na ética, no amor e respeito à vida como veículos, sendo os fóruns participativos, como a Eco-Negociação (metodologia desenvolvida pelo Instituto de Pesquisas Ecológicas - IPÉ, em 2001, e que já está em sua 6ª edição) e o Conselho Juruti Sustentável (idealizado no âmbito da proposta de desenvolvimento local para o município de Juruti pela Fundação Getúlio Vargas, Alcoa e Fundo Brasileiro para a Biodiversidade) respostas possíveis ao engajamento e a participação cidadã em Uruçuca.

\section{Indicadores de Sustentabilidade para municípios e a Participação Social}

revista brasileira de educação ambiental

A Agenda 21 Global, assinada em 1992 por 179 países durante a II Conferência das Nações Unidas sobre o Meio Ambiente e o Desenvolvimento (CNUMAD), mais conhecida como Rio-92, pode ser considerada o marco mundial na decisão de utilizar indicadores de avaliação do desenvolvimento 
sustentável. Segundo ela, os métodos para avaliar as interações entre diferentes parâmetros setoriais ambientais, demográficos, sociais e de desenvolvimento não estavam suficientemente elaborados e tampouco identificava os indicadores de desenvolvimento sustentável que deveriam ser construídos para fornecer bases sólidas para a tomada de decisões em todos os níveis (UN, 2014).

Esse documento também reconheceu que os problemas e suas soluções têm raízes nas atividades locais e que a participação e a cooperação dos governos é imprescindível para a sua implementação. Por isso, propôs a criação da Agenda $21 \mathrm{Local}$, um instrumento de planejamento de políticas públicas para o desenvolvimento sustentável local, por meio de processo participativo de consulta pública.

Pode-se observar, a partir desse momento, o surgimento de uma série de estudos, debates e acordos nacionais, transnacionais e globais incentivados por ambas as Agendas, que foram evoluindo e se transformando ao longo desses vinte anos. Atualmente, são quatro as principais organizações existentes no mundo e no Brasil que discutem o tema, que se apoiam e trabalham juntas em alguns momentos, e que possuem sistemas de indicadores que buscam entender o desenvolvimento sustentável dos municípios, que são os grandes promotores do desenvolvimento de sua região, estado e país. São elas: UN-Habitat e os Objetivos de Desenvolvimento do Milênio (ODM's) que foram substituídos em 2015 pelos Objetivos do Desenvolvimento Sustentável (ODS's); ICLEI - Local Governments for Sustainabilty e STAR Community Rating System; Global Cities Institute (GCI) e Global City Indicators Facility (GCIF); e, Programa Cidades Sustentáveis (PCS) e Indicadores PCS (VICENTE, 2014).

No Brasil, uma plataforma de indicadores de sustentabilidade que se destaca pelo pioneirismo, caráter participativo e customização às especificidades locais são os indicadores de Juruti. Elaborado pelo Centro de Estudos em Sustentabilidade (CES) da Fundação Getúlio Vargas (FGV) em conjunto com a população de Juruti, em 2009, com o propósito de monitorar as transformações ambientais, econômicas e sociais no município paraense em função da implantação de um grande empreendimento para a extração de bauxita na região, o projeto buscou retratar os temas considerados prioritários para o desenvolvimento sustentável de Juruti, na visão dos Jurutienses, o que demandou um grande esforço para coleta de dados primários e oficinas de percepção em todas as comunidades da área urbana e rural. Mais de 500 pessoas foram envolvidas em dois anos de trabalho, que se desenvolveu por meio de pesquisas, bibliográficas e de campo, e de diversas oficinas e reuniões.

Além de alimentar espaços públicos de articulação política, como os conselhos municipais, subsidiar e orientar as políticas públicas municipais, estaduais e federais, e o investimento social de instituições privadas que atuam na região, a experiência de Juruti demonstra que indicadores construídos de forma participativa podem ajudar a população a conhecer a situação das principais questões relacionadas ao desenvolvimento do município, assim 
como apontar caminhos e prioridades a seguir, facilitando a construção de uma agenda de desenvolvimento local de longo prazo entre as partes interessadas.

A iniciativa é fundamental na crença de que o processo de construção de indicadores e o acompanhamento das transformações sociais, ambientais e econômicas de uma região estimula a reflexão sobre a realidade local, promovendo um ambiente de aprendizado que favorece 0 empoderamento humano e social, e instrumentaliza o planejamento estratégico de instituições públicas e privadas (FGV, 2008: p.04).

De acordo com essa linha de atuação, em 2011, foram lançados o Programa Cidades Sustentáveis (PCS) e seus indicadores com o intuito de contribuir para o aumento da qualidade de vida da população e a sustentabilidade das nossas cidades por meio de uma metodologia e um conjunto de indicadores que permitem a análise sistêmica e holística de um município. Ele foi inspirado nos Compromissos de Aalborg, um acordo político europeu para o desenvolvimento sustentável de cidades, que por sua vez, inspiraram-se na Agenda 21 Local. Em 2014, o Programa deu um passo além e lançou o Guia de Uso do Sistema de Indicadores para a Construção de Observatórios que tem como objetivo evidenciar a importância dos indicadores, das informações e conhecimentos neles contidos, para o controle social e de políticas públicas e também para a atuação dos gestores municipais (VICENTE, 2014).

O município de Uruçuca, apesar de não possuir Agenda 21 Local, é avaliado por dois sistemas de indicadores mundialmente conhecidos e aceitos. São eles: os Objetivos de Desenvolvimento Sustentável (ODM's) e o Índice de Desenvolvimento Humano Municipal (IDH-M), desenvolvido pelo UNDP (United Nations Development Programme). O primeiro tinha a intenção de reduzir a pobreza e as desigualdades e alcançar o desenvolvimento sustentável no mundo até 2015, e o segundo busca avaliar a evolução da educação, longevidade e renda da população em geral, ao longo do tempo.

Atualmente, o município também pode dispor dos Indicadores do PCS sistema mais completo que os anteriores e que inclui a maioria de seus indicadores - os quais foram respondidos, sistematizados e analisados por Vicente (2014), gerando um breve diagnóstico sobre Uruçuca. Porém, esse trabalho pode e deve ser ampliado e complementado pois "o engajamento e a participação dos cidadãos de Uruçuca, do governo local, das empresas e do terceiro setor é fundamental para que esse diagnóstico amadureça, reflita suas necessidades e seja adotado por todos" (VICENTE, 2014: p.88).

A ideia da participação como base para o fortalecimento da sociedade não é nova. (...) O Capítulo 28 da Agenda 21 ressalva que a maioria dos problemas e soluções terá maior chance de sucesso quando tratados no âmbito regional, o que depende de um processo mais efetivo de educação e mobilização da sociedade para a construção conjunta de estratégias que levem a um desenvolvimento sustentável (PADUA, 2004: p.29).

Revbea, São Paulo, V.11, № 2: 43-53, 2016.

ambiental 
Portanto, considerando a participação social uma consequência direta de um processo permanente de educação e mobilização, que tem como objetivo despertar no indivíduo o seu papel de cidadão e, consequentemente, 0 exercício da cidadania, podemos a partir dos indicadores e do diagnóstico realizado por Vicente (2014) iniciar esse processo para Uruçuca.

\section{Cidadania e Ecocidadania}

Cidadania pode ser definida como o conjunto de direitos - civis, políticos e sociais - e de deveres, que os indivíduos estabelecem para viver harmoniosamente em uma determinada sociedade. Porém, olhando para a história, sabemos que deveres podem se tornar mais rígidos e que direitos podem se tornar mais restritivos ou até mesmo serem suprimidos, fato que nos mostra que estes não são dados aos cidadãos pelos seus governantes, e sim que eles precisam ser conquistados e colocados em prática por esses. Apesar das Constituições Nacionais serem os documentos que guardam os direitos e deveres de seus cidadãos, infelizmente não podemos afirmar que os mesmos são exercidos.

A cidadania é assumida aqui, portanto, como algo que se constrói permanentemente, que não possui origem divina ou natural, nem é fornecida por governantes, mas se constitui ao dar significado ao pertencimento do indivíduo a uma sociedade, em cada fase histórica (LOUREIRO, 2008: p.75).

O grande desafio que se apresenta para todos nós atualmente é como ser cidadão em um mundo globalizado, que interliga sociedades muito diferentes em diversos aspectos, incluindo o conjunto de direitos e deveres dos seus cidadãos, e no qual podemos observar que o capital desempenha um importante papel ao conseguir eliminar todas as fronteiras para sua entrada, as quais continuam a existir para aqueles que não dispõem do mesmo. Dessa maneira, estamos transformando nosso planeta em um grande mercado global baseado em um comércio muitas vezes injusto e predatório, principalmente para populações de países economicamente pobres e, ao mesmo tempo, ricos em biodiversidade, que lidam com a corrupção em várias áreas do governo e da sociedade.

Essa dinâmica também pode ser observada no nosso dia a dia, nos transformando em consumidores apenas, fazendo com que acreditemos que a liberdade de "ir e vir", e de "ter", que o capital pode nos oferecer seja de fato aquela que merecemos e pela qual devemos lutar, independentemente das pessoas e do meio ambiente que nos cercam, nos esquecendo que tudo o que produzimos vem da natureza, pelas mãos de várias pessoas, e que à ela tudo retorna.

Hoje, já sabemos que os recursos naturais de nosso planeta são limitados, mas continuamos a nos comportar como se não o fossem. Também sabemos que é a diversidade, tanto biológica quanto humana, que torna rica e 
possível nossa existência, mas continuamos tentando padronizá-las e controlálas. Se quisermos que nossa espécie sobreviva, precisamos colocar em prática o conceito de ecocidadania o quanto antes.

Ecocidadania/cidadania planetária é um conceito utilizado para expressar a inserção da ética ecológica e seus desdobramentos no cotidiano, em um contexto que possibilita a tomada de consciência individual e coletiva das responsabilidades tanto locais e comunitárias quanto globais, tendo como eixo central o respeito à vida e a defesa do direito a esta em um mundo sem fronteiras geopolíticas (LOUREIRO, 2008: p.76).

Para tanto, precisamos analisar e rever nossos valores, como indivíduos e sociedade, e buscar a tomada de consciência e a ação capaz de transformar uma realidade a fim de melhorá-la, entendendo o papel da Educação Ambiental (para a inserção da ética ecológica e seus desdobramentos no cotidiano) e dos fóruns participativos (como espaços para o exercício da cidadania) nesses processos.

\section{Educação Ambiental e Fóruns Participativos para a transformação local}

Atualmente, ainda vivenciamos a concepção "bancária" da educação e sua contradição inerente educador-educandos, onde 0 primeiro detém supostamente o conhecimento e o transmite ao segundo por meio de narrativas que acabam por esvaziar as palavras e os conteúdos de seus significados, e onde o segundo torna-se um recipiente, pois apenas ouve, repete e busca memorizar o que ouviu, pois acredita saber menos, ou nada saber, perante o educador (FREIRE, 1987: p.57-76). Infelizmente, a Educação Ambiental está inserida nesse contexto. Portanto muitos de seus educadores acabam por atuar de maneira semelhante, tratando o meio ambiente como apenas mais um tema, desconectado da realidade dos educandos e da sua.

(...) O impacto da globalização e do padrão capitalista nas condições políticas de países economicamente subordinados, como é o caso do Brasil, faz com que a educação formal se transforme em um sistema de domesticação dos cidadãos, de modo a aceitarem o consumismo do mercado internacional, causando um aumento acentuado da miséria e da exclusão social (PADUA; SA, 2002: p.73). 
relação do ser humano com o meio ambiente, o que implica "(...) a construção de valores, conceitos, habilidades e atitudes que possibilitem o entendimento da realidade de vida e a atuação lúcida e responsável de atores sociais individuais e coletivos no ambiente" (LOUREIRO, 2008: p.69), não pode prescindir dessa educação crítica.

Portanto, a Educação Ambiental crítica deve ir além da sensibilização e da instrumentalização se de fato quiser promover a conscientização ampla sobre o tema e o exercício da ecocidadania:

Diante do que foi exposto, podemos afirmar que a simples percepção e sensibilização para a problemática ambiental e o incremento de competência técnica, voltada para a sua resolução, não expressam aumento qualitativo da consciência e do exercício de cidadania ecológica. Esse fator depende de processos coletivos de apropriação simbólica do significado da questão ambiental para a sociedade, por meio de procedimentos educacionais e culturais, e da construção de bases materiais que permitam sua concretização, pela ação democrática no EstadoNação, o que evidencia a relevância da ação de atores individuais e coletivos nos movimentos sociais e por meio da Educação Ambiental (LOUREIRO, 2008: p.91).

\section{O exemplo do Conselho Juruti Sustentável (CONJUS) e da "Eco- Negociação: um Pontal Bom para Todos"}

$\mathrm{Na}$ busca por tentar encontrar caminhos para colocar em prática uma Educação Ambiental crítica, baseada em informações e conhecimentos relevantes para a comunidade, que seja capaz de promover a participação social - integrando diversos atores sociais - e ações ecocidadãs, podemos destacar duas iniciativas de fóruns participativos no Brasil como uma maneira possível de realizar processos coletivos de apropriação simbólica do significado da questão ambiental, são elas: o Conselho Juruti Sustentável (CONJUS) e a "Eco-Negociação: um Pontal bom para todos".

O CONJUS, fórum participativo constituído em 2009 no âmbito do Projeto Juruti Sustentável, nasceu com o propósito de discutir um futuro comum de interesse público, definir ações e formular uma agenda de desenvolvimento sustentável para o município de Juruti, oeste do Pará. Inspirado nas diretrizes da Agenda 21 Local, ele é composto por diferentes atores sociais, que representam 30 instituições de Juruti e seu entorno. Seu primeiro desafio foi, em conjunto com a comunidade, criar uma visão de futuro para o município e, em seguida, construir e definir os indicadores que seriam monitorados ao longo do tempo, os quais buscam refletir se o caminho de desenvolvimento adotado é de fato aquele em prol da sustentabilidade. Com ambos instrumentos (visão e indicadores, ou seja, futuro e presente), esse conselho e a comunidade podem verificar a melhora ou a piora da situação 
socioambiental da região e dispõem de uma importante base de dados para propor ações coletivas que busquem a melhoria da qualidade de vida.

(...) Essa proposta alinha-se à concepção de espaços de articulação, em que se cria uma nova cultura democrática, no exercício conjunto e cotidiano de convivência entre diferentes, na busca de eqüidade, justiça, transparência e de eficiência do investimento social que faça sentido para todos (FGV, 2008: p.82).

Os encontros desenvolvidos pelo CONJUS buscaram seguir algumas premissas para ampliar a participação social, integrar as diferenças existentes entre os diversos grupos e promover e ampliar o engajamento. Podemos destacar a busca pela diversidade de membros que compõem o conselho, o respeito ao tempo cultural e de aprendizado da comunidade, o apartidarismo (embora representantes do poder público possam e devam fazer parte), a representatividade verdadeira de cada grupo, a maturidade do grupo inicial de parceiros para lidar com os desafios e a busca por consenso (que difere da aprovação da maioria).

O esforço em fazer valer a premissa da participação ampla e efetiva no desenvolvimento dessa parte do tripé foi refletido nas entrevistas realizadas em campo, principalmente no meio rural. Nas entrevistas realizadas nas comunidades rurais, quase todos os participantes afirmaram que participaram de uma ou mais reuniões promovidas pelo GV-CES. Em algumas entrevistas afirmaram que o livro dos indicadores é utilizado como apoio ao material didático na escola (BORBA, 2012: p.102).

Os fóruns participativos denominados 'Eco-Negociação: um Pontal bom para todos', promovidos pelo IPÊ desde 2001 na região do Pontal do Paranapanema no estado de São Paulo, e que já está em sua $6^{a}$ edição, tem se mostrado uma boa alternativa para cumprir uma das missões da Educação Ambiental de contribuir para a mudança do modelo de desenvolvimento vigente, gerando conhecimento sobre a realidade socioambiental local e global (por meio da inclusão dos diferentes atores no processo e do estímulo à transparência nas opiniões e informações) e propiciando um espaço fértil para o surgimento de iniciativas comunitárias em prol do desenvolvimento sustentável da região (por conseguir desmontar as estruturas de poder e controle existentes durante os encontros).

As Eco-Negociações costumam receber entre 70 e 100 pessoas, as quais representam o poder público, educadores, empresários, comerciantes, fazendeiros, pequenos proprietários, lideranças do MST, assentados do MST, profissionais ligados às Unidades de Conservação, técnicos ou pesquisadores do IPÊ e demais profissionais ligados à área ambiental (PADUA, 2004: p.140). A agenda do encontro se inicia com a apresentação dos trabalhos 
desenvolvidos pelas instituições que atuam na região em prol da conservação ambiental e da qualidade de vida, com o objetivo de informar e apoiar os diálogos ao longo do fórum. Por meio de ferramentas que estimulam as pessoas a expressarem suas opiniões, levantam-se quais são as deficiências, ameaças, fortalezas e oportunidades socioambientais do Pontal. Os participantes podem se dividir em pequenos grupos para debater sobre temas de seu interesse e depois apresentar seu trabalho para todos, o que gera mais conhecimento e oportunidade para as negociações e possíveis trabalhos coletivos.

Segundo Padua (2004), em estudo que avaliou a efetividade dessa ferramenta para integração entre conservação e uso sustentável dos recursos naturais no Pontal do Paranapanema, os fóruns participativos trouxeram resultados positivos e tem conseguido estimular uma atuação ecocidadã dos participantes na superação dos desafios da comunidade, com a formação de teias de relações que tornam reais as ações desejadas. Além disso, por assegurarem a igualdade de vozes durante o debate, os fóruns ajudam a tornar pública a realidade e as necessidades dos seus participantes, favorecendo a definição de estratégias conjuntas que tem maiores chances de serem atendidas pelo poder público, despertando nesses indivíduos a autoestima e a compreensão da importância do engajamento pessoal em questões coletivas.

Os fóruns participativos foram selecionados pelo IPÊ, como estratégia educacional para o Pontal, por serem uma instância de aprendizado democrático, onde todos contribuem para a construção de uma nova realidade, com base em reflexões sobre o passado e o que se busca para o futuro. A integração dos diferentes pontos de vista direcionados a objetivos comuns aumenta as chances dos participantes perceberem seus papéis transformadores. Sendo assim, o fortalecimento individual e coletivo pode se dar de forma mais acelerada, permitindo o exercício da cidadania em prol de mudanças que beneficiem aspectos socioambientais diversos. Ao serem analisados seus impactos, os fóruns podem passar a ser percebidos como ferramentas educacionais amplas, com o potencial de 'empoderar' os atores sociais envolvidos, fator importante quando se lida com ambientes conflituosos e complexos (PADUA, 2004: p.33).

Nos dois casos apresentados nesse artigo, os fóruns participativos promovidos com o intuito e a premissa de agregar diversos atores em torno do objetivo comum de transformar para melhorar suas realidades e de apoiar as ações e projetos ecocidadãos decorrentes desse processo mostraram-se, de fato, espaços propícios para tal, pois conseguiram trazer para dentro de sua estrutura, e se misturar com ela, a Educação Ambiental crítica, baseada na práxis, ou seja, no processo de realizar e refletir, gerador de conhecimentos populares e técnicos.

revista brasileira educação ambiental 


\section{Considerações Finais}

Como vimos, os fóruns participativos podem ser ferramentas com potencial de transformação intrínseco muito forte, desde que seus promotores os construam sobre as bases da inclusão, colaboração e do diálogo e pratiquem a Educação Ambiental crítica, tornando-os espaços férteis para o exercício da ecocidadania e para o surgimento de uma nova realidade.

Nesse contexto, indicadores de sustentabilidade podem ajudar a qualificar as reflexões coletivas sobre as tendências ambientais, sociais, econômicas e políticas que se observa em determinada localidade, e que se busca transformar, com embasamento técnico e científico e também com conhecimento empírico e popular, sendo muito mais do que uma ferramenta para monitorar o desenvolvimento de uma localidade a longo prazo, mas contribuindo para um processo contínuo de aprendizado e mobilização de todos, evidenciando sua grande sinergia e complementariedade aos fóruns participativos.

Dialogando com o desafio de promover ações cidadãs no município de Uruçuca em prol da sustentabilidade, após essa breve pesquisa, constatamos que o fomento à ecocidadania por meio da Educação Ambiental crítica requer a combinação de, pelo menos, três elementos-chave no território, são eles: informação qualificada e organizada (obtida por meio da sistematização em indicadores de sustentabilidade), instituições que tenham como objetivo promover a cidadania em prol de uma melhor qualidade de vida e espaços de diálogo que permitam a ampla e efetiva participação da sociedade (obtidos por meio da construção de fóruns/conselhos participativos e ações que envolvam diferentes atores). O primeiro e o segundo elemento já existem em Uruçuca, são eles: o trabalho desenvolvido por Vicente (2014) e o Instituto Nossa Uruçuca (INU), fundado em 2014 e que tem como base o monitoramento social e a prática da cidadania. $O$ terceiro elemento pode, e deve, ser construído com o apoio de outras instituições atuantes no município, governo local e a comunidade.

É nesta direção que o INU vem trabalhando. Após um ano de atuação, no qual buscou-se tornar conhecidos os conceitos de suprapartidarismo e cidadania ativa por meio de projetos com foco na construção de espaços de diálogo e no fortalecimento dos poucos existentes, o Instituto começou a ser procurado por outras instituições para fazer parte de seus projetos, os quais também demonstram uma vontade de construir espaços de diálogo por envolverem atores importantes para a história e o desenvolvimento do município, como institutos de pesquisa, empresas, governo e sociedade civil organizada.

Diante desse cenário positivo, o INU pretende elaborar junto com a comunidade uma Carta Compromisso, ou seja, uma lista de desejos (ou 
indicadores) com os quais os candidatos a prefeito(a) e a vereador(a) na próxima eleição se comprometam com a sua execução.

\section{Referências}

BORBA, M.R.M. A exploração de bauxita em Juruti (PA) e o modelo "Juruti Sustentável". Dissertação de Mestrado, Departamento de Geografia da Faculdade de Filosofia, Letras e Ciências Humanas da Universidade de São Paulo. 2012.

FGV - Fundação Getúlio Vargas. Juruti Sustentável: uma proposta de modelo para o desenvolvimento local. 2008.

FGV - Fundação Getúlio Vargas. Indicadores de Juruti: para onde caminha do desenvolvimento do município. 2010. Disponível em: http://www.indicadoresjuruti.com.br/

FGV - Fundação Getúlio Vargas. Indicadores de Juruti: Monitoramento 2011. 2012.

FREIRE, Paulo. Pedagogia do oprimido. $17^{\text {a }}$ edição. Rio de Janeiro, RJ: Paz e Terra, 1987.

LOUREIRO, C.F.B. Educação Ambiental e Movimentos Sociais na Construção da Cidadania Ecológica e Planetária. In: LOUREIRO, C.F.B.; CASTRO, P.P.L.R.S. (orgs). Educação Ambiental: repensando o espaço da cidadania. São Paulo, SP: Cortez, 2008. p.69-98.

MMA (MINISTÉRIO DO MEIO AMBIENTE). Agenda 21 Global. Preâmbulo. 1992. Disponível em:

$<$ http://www.mma.gov.br/estruturas/agenda21/ arquivos/cap01.pdf/>. Acesso em: 01 mar.2014.

PADUA, S.M. Educação Ambiental como Processo de Gestão Sócio Ambiental: Integração entre Conservação e Uso Sustentável dos Recursos Naturais no Pontal do Paranapanema. Dissertação de Doutorado, Centro de Desenvolvimento Sustentável da Universidade de Brasília. 2004.

PADUA, S.M. e SÁ, L.M.B.M. O papel da Educação Ambiental nas mudanças paradigmáticas da atualidade. Revista Paranaense de Desenvolvimento. N $^{\circ}$ 102: p.71-83, Janeiro-Junho/2002.

UN (UNITED NATIONS). World Urban Campaign: Better City, Better Life. 2014. Disponível em:

$<$ http://mirror.unhabitat.org/categories.asp?catid=709>. Acesso em: 01 mar.2014.

VICENTE, Anna C. V. Uruçuca, cidade sustentável. Trabalho de Conclusão de Curso, MBE Pós em Meio Ambiente - COPPE - UFRJ - Universidade Federal do Rio de Janeiro. 2014. 